\title{
A Case Study on BLended Learning in Engineering EDUCATION
}

\author{
Jeffrey Harris and Charles Park \\ University of Toronto \\ jharris@mie.utoronto.ca, charlestj.park@mail.utoronto.ca
}

\begin{abstract}
This paper explores a case study of implementing blended learning in a third-year engineering course. In "Mechanical and Thermal Energy Conversion Processes", blended learning was implemented by flipping the classroom (i.e. reversing the roles of lectures and homework) for selected units of the course. While flipping an entire course can be a significant undertaking, it can be much easier to take a blended approach and only flip lectures on selected topics. Many studies on flipped classroom learning have focused on the production of online lectures and active learning methods; often these case studies have overlooked the mechanisms to bring homework into the classroom. In this case study, homework was adapted into a variety of in-class activities, composed of hands-on learning, problem solving, and classroom discussions. In addition, a variety of classroom space types were used to conduct these activities. In this paper, the successes, challenges, and lessons learned for each type of activity and classroom space are discussed. Strategies for student engagement and acceptance of blended learning are also discussed.
\end{abstract}

Keywords: Blended learning, flipped classroom, inverted classroom, practice of engineering education

\section{INTRODUCTION AND BACKGROUND}

In the traditional delivery of an engineering course, the instructor teaches the course material by delivering lectures during class time, and the students complete homework and assignments on their own, outside of class time. By using the flipped classroom pedagogy, the settings of lectures and homework are reversed: students learn the course material at home (for example, through online videos), and students are engaged in activities during class time.

In a blended learning environment, students learn using a combination of different pedagogies or technologies. For the purpose of this work, we consider blended learning to consist of a mixture of traditional and flipped classroom learning.

\subsection{Student Perceptions of the Flipped Classroom}

At the start of a flipped course, students may have mixed reactions because they are immersed into a learning environment outside of their comfort zone. While teaching flipped engineering courses, Strayer, Hotle and Garrow, Mason et al., and Bland have observed an initial adjustment period, in which students adapt to a new method of learning [1-4]. Students who initially struggle to adapt can become frustrated.

At the end of a flipped course, however, engineering students have expressed positive perceptions of learning in a flipped classroom. Canino [5] and Hotle and Garrow [2] noted that students believed they learned the course material better in a flipped classroom than they would have in a traditional classroom. Moreover, Smith noted that students felt better prepared for assessments when they learned in a flipped classroom [6].

\subsection{Student Performance in Flipped Classrooms}

The literature shows mixed results about how flipped classroom learning affects students' performances on tests and exams. In a control systems (mechanical engineering) course, Mason et al. reported that students performed equally or better when the course was taught using a flipped classroom (compared to a traditional classroom) [3]. On the other hand, in a thermodynamics course, Canino compared a flipped classroom to a traditional classroom that included active learning components [5]. $\mathrm{He}$ found that between instructional methods, there was no statistically significant difference in test and exam performance. Moreover, Merrett compared two different implementations of flipped classroom: in one implementation, the at home learning was done through videos, and in the other implementation, the learning was done through the textbook [7]. Compared to traditional lecturing, students performed better on the final exam when the classroom was flipped using videos; students 
performed worse on the final exam when the classroom was flipped with the textbook. This suggests that the choice of pedagogy may not strongly affect how students perform on tests and exams; whereas, the implementation of pedagogy can strongly affect performance.

\subsection{Student Workload}

Empathetic instructors may be cognizant of how a change in the delivery of a course can affect the workload placed on the students. In flipped chemistry courses, Smith noted that students found it a burden that lectures were moved outside the classroom. Similarly, in their first iteration of a flipped environmental engineering course, Velegal et al. noted that students were concerned about the amount of time spent on the course [8]. In both of these cases, lectures were moved outside the classroom and replaced with in-class activities, such as problem solving; homework, however, was still done by students outside the classroom.

In their second iteration of teaching with a flipped classroom, Velegal et al. used class time for students to work on homework problems [8]. By bringing homework into the classroom, they found that students were no longer concerned about their workload. Hotle and Garrow taught a civil engineering systems course using both flipped and traditional classrooms [2]. With the flipped classroom, they used in-class time to work on homework problems. Students in both sections reported the amount of time they spent on the course, and the amounts were similar for each section.

These reports, ultimately, show that the student workload can be maintained at a manageable level by using a true classroom flip - a flip that effectively brings the homework into the classroom.

\subsection{Purpose}

The present paper is a case study in the practice of engineering education. Through the case study, we present anecdotal observations and lessons learned from a course taught in a blended format, with a mix of traditional and flipped classes. Our observations focus on the classes that were taught using a flipped classroom pedagogy.

The purpose of the paper is to share experiences with other practitioners of engineering education within the CEEA community. We are not presenting rigorous research on engineering pedagogy.

\section{CASE STUDY}

\subsection{Course Overview}

"Mechanical and Thermal Energy Conversion Processes" is a core course for third-year engineering science students specializing in an energy systems major at the University of Toronto. The course is taught over 13 weeks with 3 hours of lecture and 1 hour of tutorial each week. Additionally, the course contains four 3-hour laboratories. This course was taught in a blended format in 2013 (27 students enrolled) and 2015 (11 students enrolled).

The course topics included thermodynamic cycles for gas turbine systems, steam power plants, reciprocating engines, and refrigeration. Air conditioning, combustion, and fuel cells were also studied.

Lectures on reciprocating engines, air conditioning, and heat pumps were taught using a flipped classroom, and the remaining topics were taught using traditional lectures. This blended approach was less daunting to the instructor than flipping an entire course because it required a smaller time investment at the start of the term. A blended approach also allowed the instructor to experiment with different teaching methods without being committed to a specific method for an entire term.

In 2013, an anonymous mid-term survey was given to students so that they could provide the instructor with formative feedback on flipped classroom learning. The survey was completed by 11 out of 27 students.

\subsection{Video Lectures}

Khan-style lecture videos were produced on a desktop computer using an EasyPen (geniusnet.com) pen tablet. Freely downloaded software was used to record and produce videos. Ezvid (ezvid.com) was used for screen capture; SmoothDraw (smoothdraw.com) was used as a virtual whiteboard; Windows Live Movie Maker (windows.microsoft.com/en-ca/windows/movie-maker) was used for video editing. Videos were posted on YouTube. Some sample videos can be viewed online at https://goo.gl/t1PT35.

\subsection{In-Class Activities}

For classes taught using the flipped classroom pedagogy, three types of activities were used in class to create active learning experiences. These were: hands-on activities, problems solving, and class discussions.

2.3.1 Hands-on Activities. For the course unit on reciprocating engines, one class was held in the energy laboratory. Several stations were set up in the laboratory, 
and each station had a physical engine (or engine part) and a worksheet. Examples of the physical engines are shown in Fig 1. The worksheet briefly introduced the physical component and posed several questions that linked the physical item to the theory taught in the lecture videos. Students divided themselves into small groups, and during the class, the groups rotated through all the stations. At each station, student groups would complete the worksheet together. The instructor roamed around the room, interacting with students throughout the class.

2.3.2 Problem Solving. In-class assignments replaced weekly homework problem sets. This approach created active lectures while being mindful of students' workload. The assignments consisted of short qualitative "concepts \& understanding" questions followed by one large thermodynamic cycle problem. Students completed inclass assignments individually, but were encouraged to discuss the work in groups and help each other solve the problems. The assignments were graded by teaching assistants.

2.3.3 Class Discussions. Real-world examples were introduced though in-class readings and videos clips (e.g. from educational television programs). For each example, students were given a series of discussion questions. Students discussed their responses, and the instructor acted as a moderator.

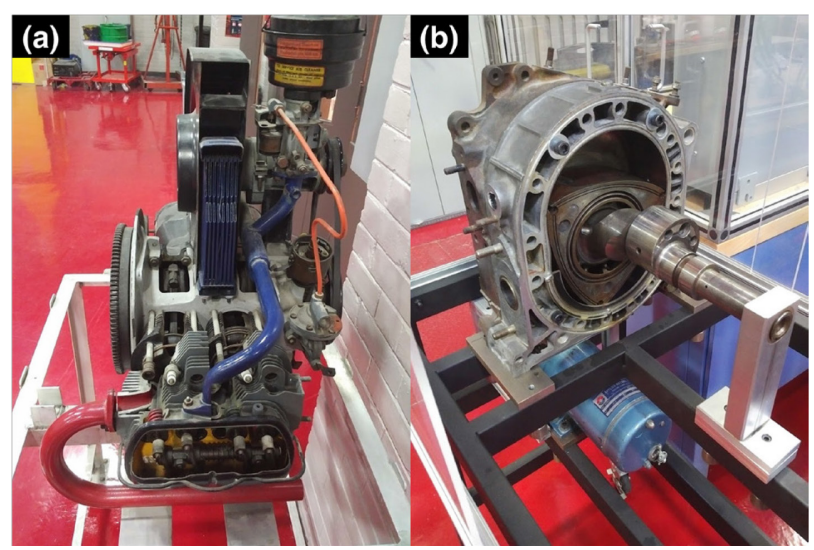

Fig 1. Examples of engines used for hand-on "stations".

(a) Cutaway of a Volkswagen air-cooled boxer engine,

(b) Cutaway of a Mazda rotary engine

\section{IMPRESSIONS OF FLIPPED LECTURES}

The qualitative perceptions of flipped classroom learning are described below from both the student and instructor perspectives. The perceptions from a student perspective were written by Charles Park, a student who took the course in 2013. Perceptions from the instructor perspective were written by Jeffrey Harris, the course instructor in 2013 and 2015.

\subsection{Student Perspective}

The flipped classroom is an innovative way to allow learning the course material, for two reasons. One reason is that it enabled me to pick up the material at my own learning rate, being able to pause or speed up the lecture video according to my own convenience. The second reason is that it allowed me to become more engaged during the actual lecture session, since the basic course material would be taught outside of the classroom so that the in-class time with the instructor could be devoted to more in-depth examination of problem solving approaches. The flipped classroom is a teaching technique that should be increasingly incorporated into courses not only in mechanical engineering, but in other areas such as programming or software design, where the emphasis can be on retaining concepts quickly after listening to the professor for the first time. However, it should also not be used all the time, since it can exasperate students if they are forced to do pre-class homework during weeks when there are many other course commitments. Ideally, the flipped classroom sessions can be scheduled after the instructor communicates with the class and assesses the overall "tone" of the class.

\subsection{Instructor Perspective}

As an instructor, one of the largest advantages of a flipped classroom was the ability to watch students do 'homework' problems in-class. While watching students solve problems, I could observe what was easy, where they got stuck, what concepts made them think longer, and where they went down a wrong path. This helped me identify aspects of a problem that were, generally, the most challenging. That allowed me, on occasion, to interrupt class to review a difficult concept. Furthermore, when I noticed a student going down a wrong path (i.e. making a crucial error early in the solution of a problem), I was able stop the student and correct his/her error. This prevented the student from propagating an early mistake through a long solution, and thereby inefficiently using his/her time.

The lack of immediacy - the inability of students to ask questions in lecture-is one criticism of the flipped classroom [2]. In other words, when a student is watching a lecture video at home, he/she is unable to put up his/her hand to ask the instructor a question. While this is a valid criticism, my response is that in a traditional classroom, students do not have immediacy (i.e. the ability to get an immediate response to a question) while doing their homework. As an instructor, I feel that students ask more questions while they are actively solving problems than they ask while passively sitting in a lecture. Therefore, I perceive that I can have a larger impact on student 
learning in a flipped classroom than in a traditional classroom

\section{LESSONS LEARNED}

\subsection{Longer Classes Better Facilitate Activities}

In 2013, classes were scheduled in 50-minute blocks. Although best efforts were made to create in-class activities that could be completed in 50 minutes, some students struggled to finish. In the mid-term survey, 3 out of 11 students said that the in-class sessions felt too rushed.

In 2015, to better accommodate in-class activities, classes were scheduled in two 110-minute blocks per week (compared to four 50-minute blocks in 2013). This created a lot more flexibility. For in-class problem solving, this allowed the instructor to assign more challenging questions. All students were able to complete their work within the 110-minute class, and extra nonassessed problems were given to students who finished early. The student experience was certainly improved from that in 2013. Therefore, the lesson learned was that 110-minute blocks were better suited for flipped classes than 50-minute blocks.

\subsection{Use In-Class Deliverables}

Initially, in-class problem solving was structured so that an assignment was handed out at the start of class and students had to submit their solutions by the end of class. When the students knew that they would have to complete a deliverable during class, they prepared and watched the lecture videos before class. In the 2013 mid-term survey, all students said that they watched the lecture videos before class. This was corroborated with the number of views each video received on YouTube.

The in class deliverables were removed for the last two assignments in 2013 because some students had difficulty completing assignments in a 50-minute time slot. When there was no deliverable during class, students were less engaged and came to class less prepared. The assignment was still handed out at the start of class, but students could take their work home and submit it at a later date. As a result, the YouTube lecture videos had very few views before class, and students came to class unprepared. During class, it was very clear that several students were not engaged: they were studying or doing homework for other courses.

Therefore, the lesson learned was to include in-class deliverables for problem solving sessions. In 2015, all active classes had in-class deliverables, and the students were prepared and engaged.

\subsection{Use Appropriate Classroom Spaces}

Active classes were held in a variety of spaces, based on room availability and university scheduling. As shown in Fig. 2, the spaces included lecture theatres, seminar rooms, classrooms with movable desks, and laboratories. All hands-on activities were conducted in laboratory spaces, and all four types of spaces worked well for class discussions.

In-class problem solving was attempted in all four types of spaces. Problem solving was most effectively done in classrooms with movable desks. In that room, the desks were arranged into groups so that students faced each other. This helped facilitate a collaborative atmosphere, and it was easy for the instructor to move around the room and interact with students. Similarly, the laboratory was a good space for collaboration and interaction, but the background noise of operating engines was distracting. On the other hand, lecture theatres and seminar rooms were not conducive to collaboration because it was hard for students to converse with their seats all facing the front of the classroom. In these rooms, it was also difficult for the instructor to roam the class and check up on students as they were working. Since the class enrollment was small, a workable solution was to have students seated in every other row. This allowed space for the instructor to walk down the empty rows to interact with students above and below.

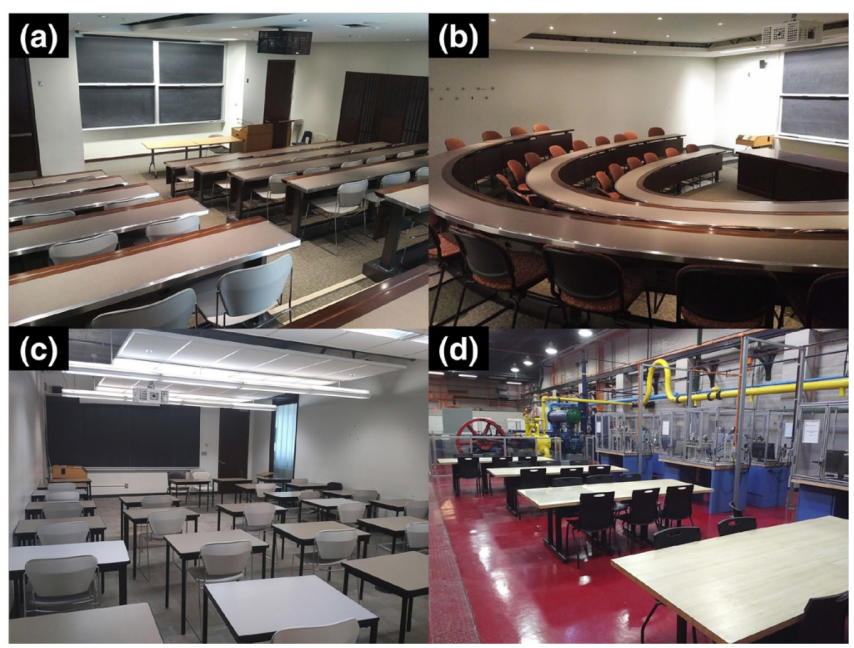

Fig 2. Classroom spaces included: (a) lecture theatre, (b) seminar room, (c) classroom with movable tables, (d) laboratory

\subsection{Sell the Pedagogy to Students}

As discussed in the introduction, other engineering educators noted that students take time to adjust to learning in a flipped classroom [1-4]. In our case, however, there was no apparent adjustment period. The 
first flipped class was preceded by a discussion about different teaching methods, including the flipped classroom pedagogy. Students seemed to appreciate the benefits of learning in a flipped classroom, and they were appreciative of the effort to help them learn better. Therefore, with a brief understanding of the pedagogy, it is possible that students more easily committed to a new learning method. Finally, the lesson learned is that getting students to "buy in" to a new way of learning may help reduce the adjustment period.

\section{CONCLUSIONS}

At the University of Toronto, blended learning was practiced by flipping a portion of a third-year energy conversion course. Both students and instructors had positive perceptions of the classes taught using the flipped classroom pedagogy. Key lessons learned include:

- Use 110 minute sessions instead of 50 minutes sessions for activity-based classes.

- Have deliverables during class time to encourage students to prepare for class and actively engage in class.

- Use classrooms with movable tables, if possible, for problem solving sessions. If fixed seating must be used, keep alternating rows empty to allow the instructor to easily circulate around the room.

- Talk to students about the flipped classroom in advance of practicing it. This can help reduce challenges associated with adapting to a new learning method.

At the end of the day, a blended approach allows students and instructors participate in a flipped classroom without a complete commitment to a particular learning method. For an instructor, flipping a class for the first time can be a significant undertaking if he/she is producing all new lecture videos and creating new in-class homework activities. Flipping only a portion of a course can significantly reduce the initial time burden on an instructor. Students, on the other hand, appreciate a variety of instructional methods. In a survey, the majority of students said that, ideally 40 to $60 \%$ of lectures in a course should use a flipped classroom. Therefore, through this case study, we have shown an example of how blended learning can work for a third-year engineering course.

\section{References}

[1] Jeremy F. Strayer, "How learning in an inverted classroom influences cooperation, innovation and task orientation," Learning Environ. Res., vol. 15, pp. 171-193, 2012.

[2] Susan L. Hotle and Laurie A. Garrow, "Effects of the traditional and flipped classrooms on undergraduate student opinions and success," J. Prof. Issues Eng. Educ. Pract., vol, 142, iss. 1, January 2016.

[3] Gregory S. Mason, Teodora Rutar Shuman, and Kathleen E. Cook, "Comparing the effectiveness of an inverted classroom to a traditional classroom in an upper-division engineering course," IEEE Trans. Edu., vol. 56, no. 4, November 2013.

[4] Larry Bland, "Apply flip/inverted classroom model in electrical engineering to establish life-long learning," in Proc. ASEE Annu. Conf., (Chicago, IL, USA; 18-21 June 2013), pp. 11.223.1-11.223.11

[5] James V. Canino, "Comparing student performance in thermodynamics using the flipped classroom and think-pairshare pedagogies," in Proc. ASEE Annu. Conf., (Seattle, WA, USA; 14-17 June 2015)

[6] J. Dominic Smith, "Student attitudes toward flipping the general chemistry classroom," Chem. Educ. Res. Pract., vol. 14, pp. 607-614, 2013

[7] Craig G. Merrett, "Using textbook readings, YouTube videos, and case studies for flipped classroom instruction of engineering design," in Proc. CEEA Canadian Engineering Education Conf. (Hamilton, ON; 31 May - 3 June 2015)

[8] Stephanie Butler Velegol, Sarah E. Zappe, and Emily Mahoney, "The evolution of a flipped classroom: evidencebased recommendations," Advances in Engineering Education, vol. 4, iss. 3, pp. 1-37, 2015 